\title{
EDITORIAL
}

\section{Ceremonia de Acción de Gracias con los graduandos de Medicina y Enfermería, diciembre 10 de 2019}

Forma de citar este artículo: Osorio C. Ceremonia de Acción de Gracias con los graduandos de Medicina y Enfermería, diciembre 10 de 2019. Med UPB. 2020;39(1):2-3.

DOI:10.18566/medupb.v39n1.a02

1 Decano, Facultad de Medicina, Escuela de Ciencias de la Salud, Universidad Pontificia Bolivariana. Medellín, Colombia.

Dirección de correspondencia: Camilo Osorio Barker. Correo electrónico: camilo.osorio@ upb.edu.co

\begin{abstract}
Thanksgiving Ceremony with Medical and Nursing graduates, December 10, 2019 / Ceremônia de Ação de Graças com os formandos de Medicina e Enfermagem, dezembro 10 de 2019
\end{abstract}

\author{
Camilo Osorio Barker ${ }^{1}$
}

Hay algunas palabras estigmatizadas, ya que usualmente se les relaciona con hechos negativos que afectan a otras personas, pero que entendidas en su connotación positiva, se convierten en cualidades necesarias para la expresión de la persona, en cualquier disciplina del conocimiento y del ejercicio profesional.

Una de ellas es la ambición, palabra normalmente asociada con una desmedida búsqueda de algo egoísta, como el dinero o el poder. Una ambición a la que no le importa a quien perjudica con tal de alcanzar su propósito, en claro ejemplo de que el fin justifica los medios.

A ese tipo de ambición definitivamente no me referiré. Hablaré de otra ambición, la sana y limpia, en una definición que debería tener toda persona, muy especialmente los jóvenes como ustedes.

Es la ambición de convertir los sueños, tan deliciosos a su edad, pero siempre necesarios, en realidades tangibles. La ambición a ser un excelente profesional, ser una buena persona, ser un agente de cambio social en la propia profesión, pero también en lo general y, lógicamente una ambición lícita hacia los medios para obtener una vida adecuada y digna para uno y su familia.

Otra palabra frecuentemente mal entendida es la competitividad. Y en el mismo sentido que la ambición, puede ser muy negativa, si se convierte en una malsana intensión de superar a los demás por el solo hecho de sentirse más que ellos, sin detenerse en la forma como se logre. Pero, no nos digamos mentiras, la vida tiene mucho de competencia, sin que esto tenga implícito la mala intensión. La competencia sana es más un estímulo para la superación personal, siendo nosotros mismos el principal competidor a superar.

Aclarados estos conceptos, puedo entonces referirme a lo que, como observador del trasegar de muchísimas generaciones durante mi carrera docente, voy concluyendo: en mis años de ejercicio universitario he tenido el placer y el orgullo de participar en la formación personal y profesional de una gran cantidad de personas; su diversidad ha sido infinita en todos los sentidos, pero especialmente en las actitudes frente a la vida, más allá que en sus capacidades, y es allí donde se marcan las mayores diferencias que conllevan consecuentemente a un desenlace futuro ampliamente diverso.

Cada día me convenzo más de la veracidad del concepto de que el mundo lo conforman dos tipos de personas: las que ven que las cosas pasan, y las que hacen que estas sucedan. Los simples testigos y los grandes ejecutores.

Cada persona va definiendo durante sus años de formación y luego en su desempeño en la sociedad, a cuál de estos grupos quiere pertenecer. No es la conformista suerte ni una predestinación inmutable lo que determina el futuro. ¡No! Es algo por lo que cada persona opta y decide. 
Es aquí donde la ambición y la competitividad toman un importante papel: marcan la diferencia entre la cómoda supervivencia y el esfuerzo del líder.

No pretendo satanizar la primera opción, ni siquiera me atrevo a calificarla como mediocridad, pero sí es cierto que la formación que ustedes han recibido en esta Universidad no tiene una orientación hacia la formación de personas "a secas". Sus profesores $\mathrm{y}$ sus familias, han trabajado para hacer de ustedes personas especiales, con ambiciones académica y humanas positivas que los lleven al triunfo, con su connotación social y de servicio a los demás. Con la clara conciencia de que en esta competencia de todos los días tienen que ser los primeros, no por el orgullo de serlo, sino por la satisfacción de ser los mejores en el servicio al paciente, en el estudio, el profesionalismo, la responsabilidad y el compromiso.

Da mucha tristeza encontrarse con personas planas y sin ambiciones, que solo buscan remar el resto de sus días en su pequeño estanque personal, sin pensar en superar los límites de su zona de confort, donde nada lo exponga a retos o dificultades, aunque tengan claro que del otro lado pueda haber mucho más.

La gracia de la vida son los retos, las dificultades y caídas que nos impulsan hacia la creatividad, que nos obligan a cambiar. ¿Qué sería de la vida sin problemas? ¿Valdría la pena?

Esperamos mucho de ustedes como generación de renovación y progreso, por eso confiamos en que enfrenten la vida con valentía y sin nunca olvidar sus sueños y ambiciones, porque cada uno de ustedes es un Líder.

Muchas gracias. 